\title{
Risk- and Sustainability-Informed Decision Making for Structures in a Life-Cycle Context
}

\author{
Dan M. Frangopol ${ }^{1}$ and Samantha Sabatino ${ }^{2}$
}

\author{
DOI: https://doi.org/10.5592/CO/BSHM2017.2.1 \\ ${ }^{I}$ The Fazlur Rahman Khan Endowed Chair of Structural Engineering and Architecture, Department of Civil \\ and Environmental Engineering, ATLSS Center, Lehigh University, Bethlehem, PA 18015-4729, US \\ ${ }^{2}$ Ph.D. Candidate, Department of Civil and Environmental Engineering, ATLSS Center, Lehigh University, \\ Bethlehem, PA 18015-4729, USA \\ E-mails: ${ }^{1}$ dan.frangopol@lehigh.edu; ${ }^{2}$ sas711@lehigh.edu.
}

\begin{abstract}
Risk-based performance metrics allow engineers to combine the probability of structural failure with the consequences corresponding to this event. A sustainability performance metric is established considering the risks associated with economic, social, and environmental impacts, utility theory, and the decision maker's risk attitude.
\end{abstract}

Keywords: risk; sustainability; bridges; multi-hazards, life-cycle; optimization; decision making

\section{Introduction}

The condition of civil infrastructure systems around the world is degrading due to a variety of deteriorating mechanisms including aging, environmental stressors, man-made hazards (e.g., blasts and fires) and natural hazards (e.g., earthquakes and hurricanes), among others. Consequently, improving the overall condition and safety of deteriorating civil infrastructure systems is a key concern worldwide. For example, in 2017, the American Society of Civil Engineers (ASCE) reported, within the Report Card for America's Infrastructure, that the average age of the United States' 614,387 bridges was 43 years. Additionally, nearly a quarter of these highway bridges were classified as either structurally deficient or functionally obsolete (ASCE 2017). These staggering statistics highlight the dire need to implement rational mitigation strategies that maintain structural performance within acceptable levels through the life-cycle of deteriorating civil infrastructure. In order to ensure adequate life-cycle performance, it is crucial to implement optimal management strategies that maintain performance of infrastructure systems within acceptable levels through their life-cycle (Okasha \& Frangopol 2009, Dong et al. 2015). Life-cycle management is widely recognized as an effective tool for maximizing the cost-effectiveness of implementing intervention actions that improve condition and safety, and extend the service life of deteriorating infrastructure systems (Ang 2011, Barone \& Frangopol 2014a, Frangopol \& Liu 2007).

\section{Risk and Sustainability in a Life-Cycle Context}

Life-cycle assessment of deteriorating infrastructure systems includes aleatory and epistemic uncertainties associated with natural randomness and inaccuracies in the prediction or estimation of reality, respectively (Ang \& De Leon 2005, Ang \& Tang 2007). Because of these uncertainties, it is imperative for structural engineers to accurately model and assess the structural performance and expected total cost within a probabilistic life-cycle context (Frangopol 2011).Furthermore, the effects of maintenance, repair, and rehabilitation on structural lifecycle performance must be quantified (Barone \&Frangopol 2014b, Frangopol \& Soliman 2016, Frangopol et al. 2004, Sánchez-Silva et al. 2016, Zhu \& Frangopol 2012, 2013). Approaches for the life-cycle management of infrastructure systems involving reliability performance indicators consider uncertainties associated with loads and resistance, but are not able to account for the consequences incurred from structural failure. Risk-based indicators provide the means to combine the probability of structural failure with the consequences associated with this event (Ang \& Tang 1984, Barone \& Frangopol 2014b, Decò \& Frangopol 2011, Sabatino et al. 2015, 2016). Furthermore, methodologies considering sustainability as a performance indicator are becoming relevant within the field of life-cycle engineering. The incorporation of sustainability in the life-cycle performance assessment and management procedures allows for the effective integration of economic, social, and environmental aspects (Bocchini et al. 2014). A sustainability performance metric may be established considering multi-attribute utility theory, which facilitates the combination of several risks while incorporating the risk attitude of the decision maker. Utility theory is employed herein to incorporate the influence of the decision maker's risk attitude on the relative desirability of lifetime management plans (Keeney \& Raiffa 1993). 
In general, utility is defined as a measure of desirability to the decision maker. Utility theory is a powerful tool used to conduct rational multi-criteria decision making analyses considering uncertain information.

\section{Utility-based decision making framework}

The schematic diagram in Figure 1 shows the utility-based decision making framework proposed by the authors. The five interconnected modules shown in Figure 1 perform specific tasks. They were applied to bridges and naval vessels. The first step of the framework involves identifying relevant structural parameters (i.e., module 1) and which stressors affect the investigated system. Some critical parameters include the structural geometry, material behavior, loading due to multiple hazards, information from SHM, and risk attitude of the decision maker. Next, the structural performance is assessed and predicted throughout the life-cycle of the investigated system (i.e., module 2). Within this step, time-variant structural performance is evaluated to determine the current and predict the future condition of various components or the entire structure. Structural performance is assessed in terms of risk and sustainability. After determining the time-variant structural performance of the system, the utility assessment of each attribute investigated within the decision making problem is conducted (i.e., module 3). Utility theory is utilized in order to depict the relative desirability of maintenance strategies to the decision maker. Attributes that are mapped to utility within this study include risk, cost, benefit, and availability. Multi-attribute utility theory is employed in order to effectively capture the sustainability performance of highway bridges and impact of the decision maker's risk attitude.

Once all investigated attributes are mapped to utility, the objective functions may be formulated, and a multicriteria optimization is carried out (i.e., module 4) with the final goal of determining optimal life-cycle management plans (i.e., when to intervene and which performance measure(s) should be implemented). In general, optimal lifetime intervention plans are obtained by carrying out a multi-criteria optimization procedure

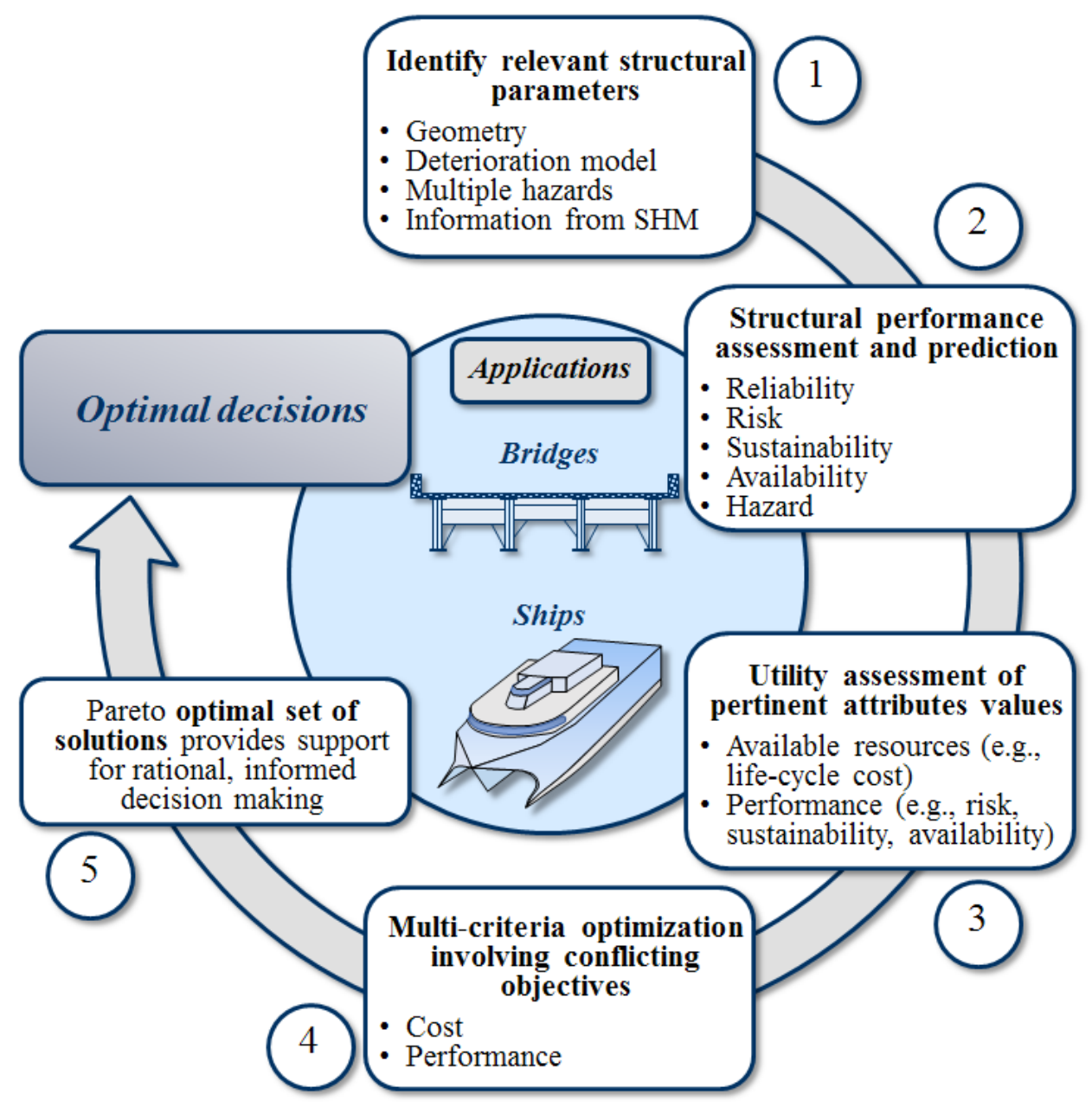

Fig 1. Risk- and sustainability-informed life-cycle decision making framework based on utility. 

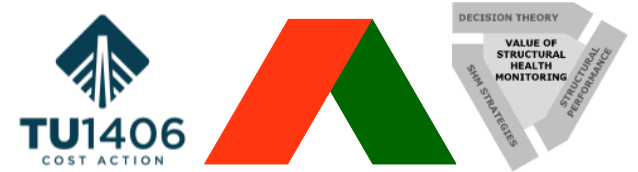

The Value of Structural Health Monitoring for the reliable Bridge Management

where the utility associated with total intervention cost and utility corresponding to performance are considered as conflicting objectives. Within this optimization procedure, the utilities associated with total life-cycle cost and performance are simultaneously maximized in order to achieve optimal lifetime management plans. The output of the optimization process, facilitated with genetic algorithms (GAs), is a Pareto optimal set of solutions which provides rational, informed intervention schedule choices to the decision maker that balances both cost and performance (i.e., module 5). Ultimately, based upon the risk attitude, preferences, and budgetary constraints of the decision maker, he/she may choose, amongst a group of trade-off solutions, an optimal intervention schedule for an investigated structural system. Overall, the proposed methodology can be used in assisting decision making regarding intervention actions that improve the performance of structural systems in a life-cycle context. Applications of the proposed utility-based decision framework to bridges can be found in Dong et al. 2015, Frangopol et al. 2017, and Sabatino et al. 2015, 2016. Also a decision making framework for optimal structural health monitoring planning of ship structures considering availability and utility has been recently proposed by Sabatino and Frangopol (2017).

\section{Conclusion}

All three aspects of sustainability (i.e., economic, social, and environmental) are crucial to the life-cycle performance assessment of civil engineering. Multi-attribute utility theory allows for the quantification of the sustainability performance of civil infrastructure systems and for risk-informed decisions.

\section{References}

Ang, A. H-S. (2011). Life-cycle considerations in risk-informed decisions for design of civil infrastructures. Structure and Infrastructure Engineering, 7(1-2), 3-9.

Ang, A. H-S., and De Leon, D. (2005). Modeling and analysis of uncertainties for risk-informed decisions in infrastructures engineering. Structure and Infrastructure Engineering, 1(1), 19-21.

Ang, A. H-S., and Tang, W.H. (1984). Probability concepts in engineering planning and design: decision, risk and reliability. Vol. II. New York: Wiley.

Ang, A. H-S., and Tang, W.H. (2007). Probability concepts in engineering: emphasis on applications to civil and environmental engineering, 2nd edition, Wiley, New York.

ASCE. (2017). 2017 Report card for America's infrastructure. American Society of Civil Engineers, Reston, VA. http://www.infrastructurereportcard.org/

Barone, G., and Frangopol, D.M. (2014a). Life-cycle maintenance of deteriorating structures by multi-objective optimization involving reliability, risk, availability, hazard and cost. Structural Safety, 48, 40-50.

Barone, G., and Frangopol, D.M. (2014b). Reliability, risk and lifetime distributions as performance indicators for life-cycle maintenance of deteriorating structures. Reliability Engineering \& System Safety, 123, 21-37.

Bocchini, P., Frangopol, D.M., Ummenhofer, T., and Zinke, T. (2014). Resilience and sustainability of the civil infrastructure: Towards a unified approach. Journal of Infrastructure Systems, 20(2), 04014004, 1-16.

Decò, A., and Frangopol, D.M. (2011). Risk assessment of highway bridges under multiple hazards. Journal of Risk Research, 14(9), 1057-1089.

Dong, Y., Frangopol, D.M., and Sabatino, S. (2015). Optimizing bridge network retrofit planning based on costbenefit evaluation and multi-attribute utility associated with sustainability. Earthquake Spectra, 31(4), 22552280 .

Frangopol, D.M. (2011). Life-cycle performance, management, and optimization of structural systems under uncertainty: accomplishments and challenges, Structure and Infrastructure Engineering, 7(6), 389-413.

Frangopol, D.M., and Liu, M. (2007). Maintenance and management of civil infrastructure based on condition, safety, optimization, and life-cycle cost. Structure and Infrastructure Engineering, 3(1), 29-41.

Frangopol, D.M., and Soliman, M. (2016). Life-cycle of structural systems: recent achievements and future directions. Structure and Infrastructure Engineering, 12(1), 1-20.

Frangopol, D.M., Dong, Y., and Sabatino, S. (2017). Bridge life-cycle performance and cost: analysis, prediction, optimization and decision making. Structure and Infrastructure Engineering, Published online on January 12, 2017,1-19, doi: 10.1080/15732479.2016.1267772. 
Frangopol, D.M., Kallen, M-J., and van Noortwijk, J. (2004). Probabilistic models for life-cycle performance of deteriorating structures: review and future directions. Progress in Structural Engineering and Materials, 6(4), 197-212.

Keeney, R.L., and Raiffa, H. (1993). Decisions with Multiple Objectives: preferences and value tradeoffs. Cambridge University Press.

Okasha, N.M., and Frangopol, D.M. (2009). Lifetime-oriented multi-objective optimization of structural maintenance considering system reliability, redundancy and life-cycle cost using GA. Structural Safety, 31(6), 460-474.

Sabatino, S., and Frangopol, D.M. (2017). Decision making framework for optimal SHM planning of ship structures considering availability and utility. Ocean Engineering, 135, 194-206.

Sabatino, S., Frangopol, D.M., and Dong, Y. (2015). Sustainability-informed maintenance optimization of highway bridges considering multi-attribute utility and risk attitude. Engineering Structures, 102, 310-321.

Sabatino, S., Frangopol, D.M., and Dong, Y. (2016). Life-cycle utility-informed maintenance planning based on lifetime functions: Optimal balancing of cost, failure consequences, and performance benefit. Structure and Infrastructure Engineering, 12(7), 830-847.

Sánchez-Silva, M., Frangopol, D.M., Padgett, J., and Soliman, M. (2016). Maintenance and operation of infrastructure systems: A review. Journal of Structural Engineering, 142(9), F4016004, 1-16.

Zhu, B., and Frangopol, D.M. (2012). Reliability, redundancy and risk as performance indicators of structural systems during their life-cycle. Engineering Structures, 41, 34-49

Zhu, B., and Frangopol, D.M. (2013). Risk-based approach for optimum maintenance of structures under traffic and earthquake loads. Journal of Structural Engineering, 139(3), 422-434.

\section{Acknowledgements}

The authors are grateful for the financial support received from the U.S. National Science Foundation Grant CMMI 1537926 and the U.S. Office of Naval Research (ONR) Awards N00014-08-1-0188, N00014-12-1-0023, and N00014-16-1-2299. The opinions and conclusions presented in this paper are those of the authors and do not necessarily reflect the views of the sponsoring organizations. 